\title{
IMPACT OF GLOBAL CLIMATE CHANGE ON HUMAN HEALTH AND RISK PREVENTION
}

\author{
Dr.Asis De (India) \\ Dr. Abhijit De (India) \\ Dr. Jenny Pun (Nepal)
}

\begin{abstract}
Many factors influence the world's atmosphere and climate. Due to human activity, the concentration of "green house" gases is increasing resulting in rise of earth's surface temperature. As a result of global warming, the eco system is changing, having adverse impact on our lives. Some increased health risk will be due to extreme weather events, while other problems will involve continual climate modification as consequences from ecological disruption or resulting from climate-induced economic disruption, e.g. traumatic, infectious, nutritional, psychological and other health consequences. Population, certain age groups such as elderly, women, children and vulnerable group, is at risk. For instance, there are risks of extreme temperatures and heat-wave, increased allergic disorders, hay fever, asthma due to air pollution, particulate matters and smog. In addition, due to flooding food-borne illnesses, water-borne illnesses, diarrheal diseases, increase in vector-borne diseases transmitted by Mosquitoes and mice e.g. Malaria, Filaria, Dengue fever, etc. There is compromise in food safety due to contaminated food with pesticide and bacteria resulting in food poisoning. Lifestyle and behavior are likely to be affected due to loss of social cohesion, increase in crime, accidents, anxiety, depression, stress, self harm and possible suicide, drug and alcohol misuse. Preventive measures will include assessment of the vulnerability of human health and mitigation measures. The health sector needs to play a key role in disease prevention, health education, disaster preparedness and effective measures to treat early evidence of impact affecting health.
\end{abstract}

KEYWORDS: Climate change, health impact, risk prevention

\section{INTRODUCTION}

The world's climate is an integrated system. Many factors influence the atmosphere's uptake and distribution of heat energy. Carbon dioxide, water vapour, and methane absorb outgoing re-radiated infrared radiation, because of this earth's surface temperature rises. Human activity is also increasing the concentration of these 'greenhouse' gases, resulting in progressive increase in earth's temperature. As per current trend, the global temperature could rise by 2 degree Celsius by 2030 AD.

Global warming is changing the earth's regular pattern of atmospheric condi- 
tions and its fluctuations, the Earth's climate. ${ }^{1,2}$

\section{THEME: HEALTH IMPACTS}

There will be different kinds of health impacts which can result from climate change, directly as a result from weathr extremes. Then changes in both temperature and humidity will play an important role on human health.

There will be some increased health risk due to extreme weather conditions, but many problems will be due to continual climate modification or as consequences from ecological disruption. Health risks increase as a consequence from climate-induced economic disruption, e.g. traumatic, infectious, nutritional, psychologicalchanges when populations are demoralised and displaced by the environmental decline and conflict situations.

\section{POPULATION AT RISK}

Usually affected population are from extremes of age; elderly and children due to immature immune response, women, especially pregnant and breastfeeding women, the obese \& who has medical condition or is immune-compromised especially cardiovascular disease ,those who are not acclimatized, e.g. new born, athletes and other participants in outdoor recreational activities, mentally ill, disabled and homeless, physically unfit - reduced vital capacity, socio-economically disadvantaged, manual labourers and outdoor workers

\section{HEALTH IMPACTS}

Direct: These health impacts have clear climate-health relationships due to effects of extreme temperatures and heat-wave e.g. Heat cramps - muscular pains and spasms, Heat exhaustion - body fluids are lost through heavy sweating, Heat stroke - is life threatening.

There could be more deaths and increased disease risk due to very hot days. The positive side or the benefits in some place could be fewer winter deaths and disease events. ${ }^{3}$

A European study of hospital admission data for a dozen major cities found that for every 1 degree Celsius rise in temperature, hospital admissions for respiratory and asthma-related illness increase up to $4.5 \%$ among the elderly. $4,5,6$

The Russian heat wave of 2010 doubled the death rate in Moscow to 700 people per day during the heat wave

During the summer 1995 heat wave in Chicago, it is estimated there were 700 excess deaths due to heat. ${ }^{7,8}$

\section{AERO-ALLERGEN PRODUCTION}

Higher temperatures and changed humidity may make the growing seasons shorten for some plants which might result in longer pollen season thereby increase allergic disorders, including hay fever and asthma. ${ }^{9}$

\section{STORMS AND FLOODS}

There were nearly 100,000 flood related deaths, and 1 to 2 billion people were 
affected by flooding during 1992-2001, some health consequences arise during or soon after the flooding, these include injuries, communicable diseases, or exposure to toxic pollutants. As a result of overflowing water excessive rainfall also facilitates entry of human sewage and animal wastes into waterways and drinking water supplies, increasing the risk of water-borne diseases. Other effects of flooding may appear later these include malnutrition, caused by crop loss, and mental health disorders resulting from the stress of flood-related problems. 8,10,11

\section{HEALTH EFFECTS OF CLIMATE CHANGE}

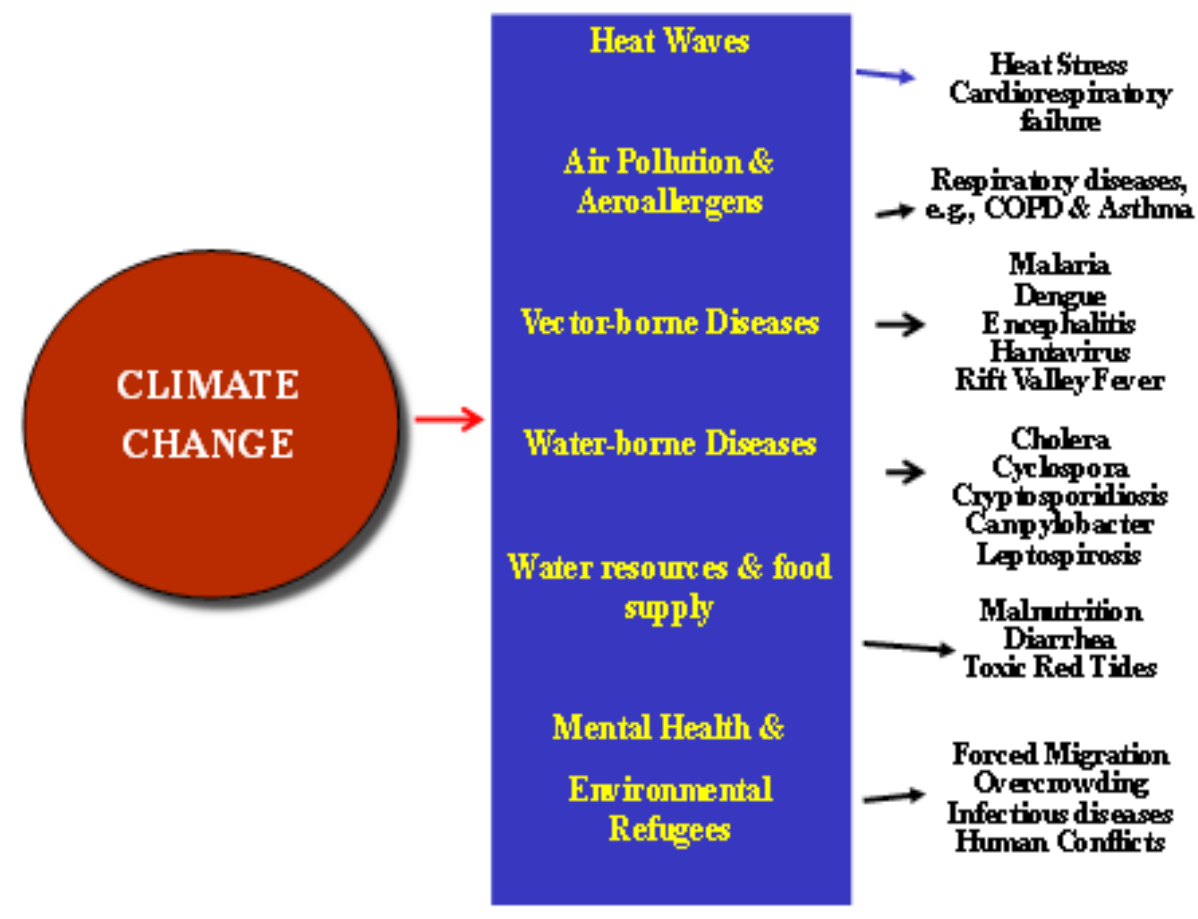

Flow diagram No. 1 shows the impact of climate change on human health

\section{PUBLIC HEALTH ISSUES -FLOODING}

Increased risk from contamination of certain food crops with faeces from nearby livestock or wild animals following heavy rain and flooding resulting food-borne illnesses e.g. Salmonellosis, diarrheal diseases and waterborne illnesses caused by pathogens e.g. Cryptosporidium and Giardia due to contamination in drinking water and through recreational use.

Flooding also contaminate drinking water, groundwater aquifers, increase concentration of chemical contaminants, formation of toxic algal bloom and water-borne Infection. $8,10,11$

\section{VECTOR-BORNE DISEASE AND CLIMATE ASSOCIATION}

A vector is an insect or any living carrier that transmits an infectious agent. A vector is required for part of the parasite's developmental cycle and transmission of the parasite directly to subsequent hosts. Most common vectors are arthro- 
pods, domestic animals, or mammals that assist in transmitting parasitic organisms to humans .Climate change enhance the breeding of insects e.g., mosquitoes and increase the risk of vector-borne diseases e.g., West Nile virus. Hotter, more humid weather affect both vector and pathogen, shortens mosquito breeding cycles. The incubation of dengue virus is speeded up by increased temperatures. Milder winters also allow the survival of many disease related organisms

Vector-borne diseases have been shown to be associated with changing climate conditions, especially El Nino-Southern Oscillation (ENSO) events.

Many infectious agents, vector organisms, non-human reservoir species, and rate of pathogen replication are sensitive to climatic conditions

Salmonella and cholera bacteria, for example, proliferate more rapidly at higher temperatures, salmonella in animal gut and food, cholera in water

In regions where low temperature, low rainfall, or absence of vector habitat restrict transmission of vector-borne disease, climatic changes could trigger epidemics in regions as follows:

Malaria - South Africa, Columbia, Venezuela

Dengue fever - Asia-Pacific

Ross river virus - Australia

West Nile - Numerous places, including U.S.A.

Dengue fever was thought to be eradicated in the U.S.A., but has comeback. Classic dengue fever is present in northern Mexico and is occurring in Texas. ${ }^{8,12,13,14,15}$

\section{THE INFECTIOUS DISEASES}

Infectious diseases can be carried by many different organisms; among them are ticks, flies and mosquitoes. When the climate becomes warmer such organisms called vectors such as ticks, flies and mosquitoes can breed easier in the warmer wetter climates.As climate change begins to affect our planet to a greater extent, the infectious disease carrying organisms will be able to reach higher altitudes and have a longer season of breeding, increasing the likelihood of human contact with the disease. There will be increase in incidence of Malaria, Viral encephalitis, Leishmaniasis, Lyme disease, Cholera, Dengue fever, Schistosomiosis, Cryptosporidiosis etc.

Also, as the climate warms up the amount of algae and fish that produce toxins poisonous to humans will proliferate. ${ }^{1,8,12,16,17}$

\section{HUMAN HEALTH AND ATMOSPHERIC AIR}

Climate change may indirectly affect the concentration of particle pollutionalso known as "particulate matter,"or PMin the air by affecting natural or "biogenic" sources of PM such as wildfires and dust from dry soils. Weather has a major role in the development, transport, dispersion and deposition of air pollutants and fine particulate matter. Particle pollution also is the main cause of visibility impairment (haze) in the major metropolis, megacities and industrial complexes.

Airflow on edges of a high-pressure system can transport ozone precursors. Ozone levels are increasing in many areas. Due to global warming, the amount 
of smog that is created by nitrous oxide, or ozone that is near the ground, will increase. An increase in fire events will increase toxic gases and particulates. Changes in wind pattern may increase long-range transport of air pollutants. Weather patterns can enhance urban "heat islands" which can lead to elevated pollution levels. An increase in the amount of smog near the ground level could potentially result in warm summer days. Smog can increase the potential of lung infection which can lead to death.

As Ozone will cause pneumonia, chronic pulmonary obstructive diseases, asthma, allergic rhinitis, particulate matter (PM) is known to affect morbidity and mortality, Toxic gases and PM from fires contribute to acute and chronic respiratory illness as evident from 1997 Indonesia fires. Wind blown dust (respirable particles, trace elements) from desert regions can affect populations in remote areas. $1,3,8,18$

\section{DROUGHTS}

Droughts represent the other extreme of weather related precipitation problems. Globally, disaster effects are greatest for droughts and associated famines which affects much larger area than flood-related regions

\section{CLIMATIC CHANGE AND FOOD SAFETY}

Use of pesticides to curtail mosquito breeding and insect control in agricultural fields can contaminate vegetables and food products resulting in food poisoning. Higher temperature increases proliferation of bacterial pathogens like Salmonella, Campylobacter and increases mycotoxins and aflatoxins in food. ${ }^{10,11,19,20}$

\section{SOCIAL IMPACTS OF CLIMATE CHANGE}

Lifestyle and human behaviour are likely to be affected by Increased ambient temperatures in the following ways; increases in crime particularly involving aggression, accidents in workplace and traffic. Hot nights may cause sleep deprivation.

Mental Health can be impacted by loss of social cohesion, anxiety and depression, tress, self harm and possible suicide, drug and alcohol abuse. $1,8,10,16$

\section{PREDICTIONS FOR THE FUTURE}

The Hadley Center for Research on Climate Control has made following predictions about the future and results of climate change worldwide by the 21st century;

The surface temperature globally will rise at an average of $3.2^{\circ}$ at a minimum of $.3^{\circ}$ Celsius

The mean daily precipitation will increase by .2 millimeters.

The mean soil moisture will decrease by a mean of 2 millimeters of moisture.

The sea level will decrease by a mean of .42 meters.

The volume and area of arctic sea ice will decrease.

The anticipated consequences will be an increase in infectious diseases, malnutrition, mental health problems, injury and violent death from conflict. 
The estimated deaths and DALY (Disability-Adjusted Life Year) due to climate change can be estimated from the WHO burden of disease graph comparing the present scenario and estimated in future by $2030 \mathrm{AD} .1,8,21,22,23$

\section{Estim ated deaths and DALYs attributable to clim ate change}

Selected health outcomes in developing countries

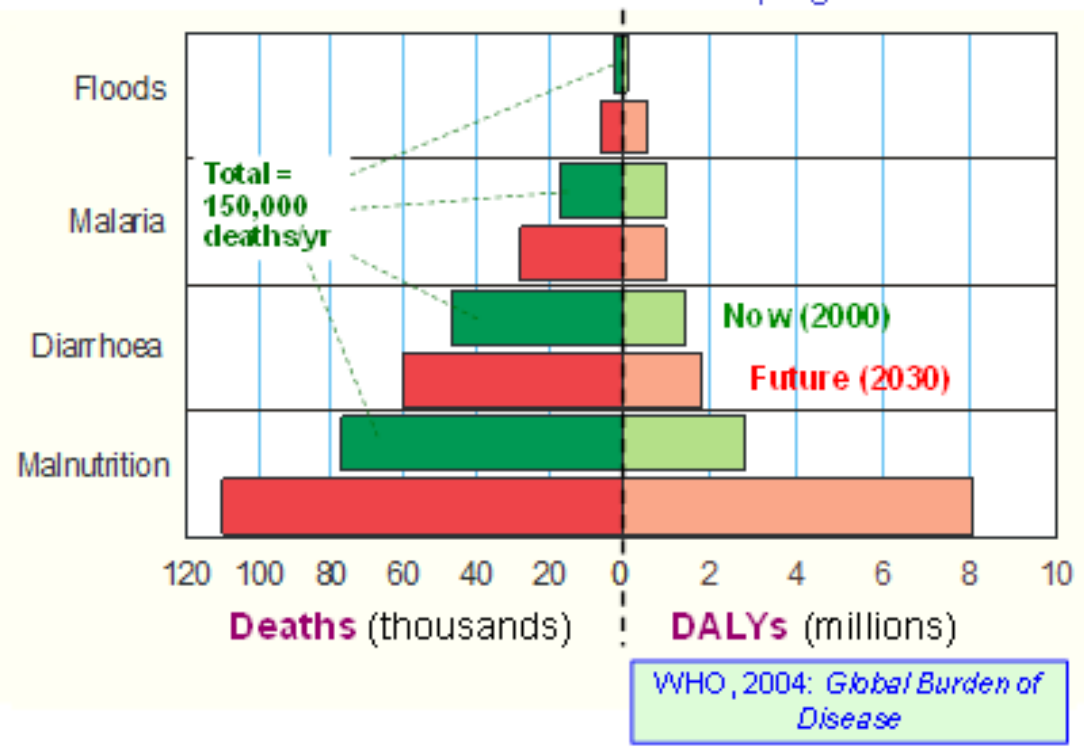

\section{RISING TO THE CLIMATE CHALLENGE}

Climate change has already causing a significant burden in developing countries and unmitigated climate change is likely to cause significant public health impacts from existing health conditions like diarrhea, malnutrition, and vectorborne diseases by 2030 .

We need to consider adaptation of mitigation and intervention options to counter the vulnerability of human health, estimate the current burden of climate-sensitive diseases and future health impacts attributable to climate change. $8,21,23,24,25$

\section{TASKS FOR HEALTH CARE SYSTEM}

It involves primarily preventing onset of health impact, to take appropriate preventative measures in response to evidence of impact in early diagnosis and prompt treatment. Similarly, it also involves taking actions to lessen the health effects by public education, disaster preparedness, surveillance of disease occurrence and risk factors, forecasting of likely future health risks and engage in intersectoral discussions and policy development.

\section{REFERENCES}

1. Aron JL, Patz JA, eds. (2001). Ecosystem change and public health: a global perspective. Baltimore: Johns Hopkins University Press.

2. Campbell-Lendrum D, Pruss-Ustun A, Corvalan C. (2003). How much 
disease could climate change cause?. In :McMichael AJ, Campbell- Lendrum D, Corvalan C, Ebi KL, Githeko AK, Scheraga JS, eds. Climate change and health: risks and responses. Geneva: WHO: 133-155.

3. Kovats RS, Campbell-Lendrum D, Matthies F. (2005). Climate change and human health: estimating avoidable deaths. Risk Anal: 25:1409-1418

4. Bouchama A. (2004). The 2003 European heat wave. Intensive Care Med 30: 1-3. Pub Med

5. Conti S, Meli P, Minelli G, Solimini R, Toccaceli V, Vichi M, et al. (2005). Epidemiologic study of mortality during the Summer 2003 heat wave in Italy. Environ Res.: 98:390-399

6. Institut de Veille Sanitaire. (2003). Impact sanitaire de la vague de chaleur en France survenue en août. Département des maladies chroniquesettraumatismes, Département santé environment, Paris.

7. Curriero FC, Heiner KS, Samet JM, Zeger SL, Strug L, Patz JA. (2002). Temperature and mortality in 11 cities of the eastern United States. Am J Epidemiol 155: 80-87. Pub Med

8. Climate Change and Human Health -Risks and Responses Summary. (2003). WHO,WMO,UNEP ; WHO, Geneva.

9. Beggs P. (2004). Impact of climate change on aeroallergens: past and future. Clin Exp Allergy 34: 1507-1513. Pub Med

10. Reacher M, McKenzie K, Lane C, et al. (2004). Health impacts of flooding in Lewes: a comparison of reported gastrointestinal and other illness and mental health in flooded and non-flooded households. Commun Dis Public Health 7: 39-46. Pub Med

11. Milly PC, Wetherald RT, Dunne KA, Delworth TL. (2002). Increasing risk of great floods in a changing climate. Nature 415: 514-517. Pub Med

12. Task Force on Climate and Health. El Niño and health. (1999). Geneva: World Health Organization.

13. Kovats S, Bouma MJ, Hajat S, Worrell E, Haines A. (2003). El Nino and health. Lancet 361: 1481-1489

14. Kovats RS, Campbell-Lendrum D, McMichael AJ, Woodward A, Cox J. (2001). Early effects of climate change: do they include changes in vectorborne disease?. Philos Trans R Soc B. 356: 1057-1068

15. Sutherst RW. (2004). Global change and human vulnerability to vector-borne diseases. Clinical Micro biology Rev. 17: 136-173. Pub Med.

16. Pascual M, Dobson A. (2005). Seasonal patterns of infectious diseases. PLoS Med. 2: e5. Pub Med.

17. Haines A, Patz J. (2004). Health effects of climate change. J Am Med Assoc. 291: $99-103$

18. Koren HS, Utell MJ. (1997). Asthma and the environment. Environ Health Perspect 105: 534-537. Pub Med.

19. Rose JB, Epstein PR, Lipp EK, Sherman BH, Bernard SM, Patz JA. (2001). Climate variability and change in the United States: potential impacts on water and foodborne diseases caused by microbiologic agents. Environ Health Perspect 109 (suppl 2): 211-221. Pub Med. 
20. Kovats RS, Edwards SJ, Hajat S, et al. The effect of temperature on food poisoning: a time-series analysis of Salmonellosis in ten European countries. Epidemiol Infect 2004; 132: 443-453. Pub Med

21. Haines, R.S. Kovats, D. Campbell-Lendrum, C. Corvalan. (July 2000). Climate change and human health: Impacts, vulnerability and public health Public Health Volume 120, Issue 7: 585-596.

22. Paul R. Epstein, M.D., M.P.H. (October 6, 2005). Climate Change and Human Health. N Engl J Med 353: 1433-1436..

23. Prof Anthony J McMichael PhD, Rosalie E Woodruff PhD, Simon Hales PhD. (11 March 2006). Climate change and human health: present and future risks. The Lancet 367.9513: 859-869.

24. Spotlight: Climate Change Health risks, present and future, from global climate change SPOTLIGHT BMJ 2012; 344 doi: http://dx.doi.org/10.1136/ bmj.e1359 (Published 19 March 2012)

25. Will.R.Bethany A.Bradley et al. (Sept. 2010). Climate Change: helping nature survive the human response Conservation Letters 3.5: 304-312.

\section{ABOUT THE AUTHORS}

Dr. Asis De is a Professor of Community Medicine at Manipal College of Medical Sciences Pokhara, Nepal. He receivd his MBBS from Calcultta University in 1974 and MD in Preventive and Social Medicine from Nagpur University in 1985. He has also worked with SSAU (a World Bank Project) as Epidamiologist and In-Charge, as a Consultant with UNISEF, and with Army Medical Corps. He has also involvd with research works and published numerous articles in national and international journals.Email: dr_asisde@hotmail.com

Dr. Abhijit De is an Intern at Manipal Teaching Hospital, Pokhara, Nepal.

Dr. Jenny Pun is a Resident at Manipal Teaching Hospital, Pokhara, Nepal. 